Article

\title{
The Diabetes Transition of Hospital Care (DiaTOHC) Pilot Study: A Randomized Controlled Trial of an Intervention Designed to Reduce Readmission Risk of Adults with Diabetes
}

\author{
Daniel J. Rubin ${ }^{1, *(D)}$, Preethi Gogineni ${ }^{1}$, Andrew Deak ${ }^{2}$, Cherie Vaz ${ }^{1}$, Samantha Watts ${ }^{2}$, Dominic Recco ${ }^{2}$, \\ Felicia Dillard ${ }^{2}$, Jingwei Wu ${ }^{3} \mathbb{D}$, Abhijana Karunakaran ${ }^{1}$, Neil Kondamuri ${ }^{1}$, Huaqing Zhao ${ }^{4}$, Mary D. Naylor ${ }^{5}$, \\ Sherita H. Golden ${ }^{6}$ and Shaneisha Allen ${ }^{1}$
}

check for updates

Citation: Rubin, D.J.; Gogineni, P.; Deak, A.; Vaz, C.; Watts, S.; Recco, D.; Dillard, F.; Wu, J.; Karunakaran, A.; Kondamuri, N.; et al. The Diabetes Transition of Hospital Care (DiaTOHC) Pilot Study: A Randomized Controlled Trial of an Intervention Designed to Reduce Readmission Risk of Adults with Diabetes. J. Clin. Med. 2022, 11, 1471. https://doi.org/10.3390/jcm11061471

Academic Editor:

Manuel Aguilar-Diosdado

Received: 4 January 2022

Accepted: 4 March 2022

Published: 8 March 2022

Publisher's Note: MDPI stays neutral with regard to jurisdictional claims in published maps and institutional affiliations.

Copyright: (C) 2022 by the authors Licensee MDPI, Basel, Switzerland. This article is an open access article distributed under the terms and conditions of the Creative Commons Attribution (CC BY) license (https:// creativecommons.org/licenses/by/ $4.0 /)$
1 Section of Endocrinology, Diabetes, and Metabolism, Lewis Katz School of Medicine, Temple University, Philadelphia, PA 19140, USA; gpreethi7@gmail.com (P.G.); cherielisa.vaz@tuhs.temple.edu (C.V.); abhijanakaru@gmail.com (A.K.); nkondamuri@gmail.com (N.K.); shaneisha.allen@tuhs.temple.edu (S.A.)

2 Lewis Katz School of Medicine, Temple University, Philadelphia, PA 19140, USA; andrew.deak@temple.edu (A.D.); samanthawatts0711@gmail.com (S.W.); dprecco@bidmc.harvard.edu (D.R.); felicia.dillard@temple.edu (F.D.)

3 Department of Epidemiology and Biostatistics, College of Public Health, Temple University, Philadelphia, PA 19140, USA; tug30693@temple.edu

4 Department of Biomedical Education and Data Science, Lewis Katz School of Medicine, Temple University, Philadelphia, PA 19140, USA; zhao@temple.edu

5 School of Nursing, University of Pennsylvania, Philadelphia, PA 19104, USA; naylor@nursing.upenn.edu

6 Division of Endocrinology, Diabetes, and Metabolism, Department of Medicine, Welch Center for Prevention, Epidemiology, and Clinical Research, Johns Hopkins University School of Medicine,

Baltimore, MD 21205, USA; sahill@jhmi.edu

* Correspondence: daniel.rubin@tuhs.temple.edu

\begin{abstract}
Hospital readmission within 30 days of discharge (30-day readmission) is a high-priority quality measure and cost target. The purpose of this study was to explore the feasibility and efficacy of the Diabetes Transition of Hospital Care (DiaTOHC) Program on readmission risk in high-risk adults with diabetes. This was a non-blinded pilot randomized controlled trial (RCT) that compared usual care (UC) to DiaTOHC at a safety-net hospital. The primary outcome was all-cause 30-day readmission. Between 16 October 2017 and 30 May 2019, 93 patients were randomized. In the intention-to-treat (ITT) population, $14(31.1 \%)$ of 45 DiaTOHC subjects and $15(32.6 \%)$ of 46 UC subjects had a 30-day readmission, while 35.6\% DiaTOHC and 39.1\% UC subjects had a 30-day readmission or ED visit. The Intervention-UC cost ratio was $0.33(0.13-0.79) 95 \% \mathrm{CI}$. At least $93 \%$ of subjects were satisfied with key intervention components. Among the 69 subjects with baseline $\mathrm{HbA} 1 \mathrm{c}>7.0 \%$ (53 mmol/mol), 30-day readmission rates were $23.5 \%$ (DiaTOHC) and 31.4\% (UC) and composite 30 -day readmission/ED visit rates were $26.5 \%$ (DiaTOHC) and $40.0 \%$ (UC). In this subgroup, the Intervention-UC cost ratio was $0.21(0.08-0.58) 95 \% \mathrm{CI}$. The DiaTOHC Program may be feasible and may decrease combined 30-day readmission/ED visit risk as well as healthcare costs among patients with $\mathrm{HbA} 1 \mathrm{c}$ levels $>7.0 \%(53 \mathrm{mmol} / \mathrm{mol})$.
\end{abstract}

Keywords: rehospitalization; transition care; pilot study; prospective randomized trial

\section{Introduction}

Hospital readmission within 30 days of discharge (30-day readmission) is a highpriority quality measure and cost target [1]. People living with diabetes are at higher 30-day readmission risk than those without diabetes [2-4]. Several interventions have shown promise for reducing the readmission risk of diabetes patients in mostly observational studies [4]. Selecting patients at high readmission risk for intervention may enable a more efficient use of resources than applying interventions broadly without regard to readmission risk. No previously published randomized controlled trials (RCTs) have tested an 
intervention designed to reduce readmission risk in patients with diabetes and high readmission risk as predicted by a validated tool. We previously reported on the development and validation of the Diabetes Early Readmission Risk Indicator (DERRI ${ }^{\mathrm{TM}}$ ) [5-7], which predicts 30-day readmission risk in diabetes patients. The aim of the current pilot RCT was to explore the feasibility and potential efficacy of a novel, multi-component intervention, the Diabetes Transition of Hospital Care (DiaTOHC) Program, on 30-day readmission risk in adult patients with diabetes at high risk based on the DERRI ${ }^{\mathrm{TM}}$.

\section{Materials and Methods}

\subsection{Study Design, Setting, and Ethics}

This was a non-blinded pilot RCT with two parallel arms that compared usual care (UC) to the DiaTOHC Program (Intervention) at Temple University Hospital, an urban, academic, safety-net hospital in Philadelphia, PA. The protocol was registered in the National Clinical Trials Registry (NCT03243383) and approved by the Temple University Institutional Review Board (\#24306). This study was carried out in accordance with the Declaration of Helsinki. Written informed consent was obtained from all subjects. The study was registered on ClinicalTrials.gov (NCT03243383), where the protocol is accessible.

\subsection{Participants and Randomization}

Inclusion criteria were an established diagnosis of diabetes, defined by preadmission use of a diabetes-specific medication and/or documentation of the diagnosis in the medical record, age $\geq 18$ years, high predicted risk of 30 -day readmission $(\geq 27 \%$ ) based on the $\operatorname{DERRI}^{\mathrm{TM}}$ [6], and hospital admission to a non-critical care unit. Exclusion criteria were pregnancy, binge drinking (at least 5 alcoholic drinks for males or 4 alcoholic drinks for females on the same day), drug abuse within 3 months before admission, receiving palliative care during the hospitalization, participation in another readmission risk reduction program, planned or actual transfer to another hospital or subacute facility, discharge expected within $12 \mathrm{~h}$, lack of access to a phone, living more than 30 miles away from the hospital, $\mathrm{HbA} 1 \mathrm{c}<5.7 \%$ (39 mmol/mol), and inability to speak English. After enrollment, subjects were excluded upon transfer to another hospital or subacute facility, discharge to hospice or a long-term care facility, signing out against medical advice, or inpatient death. We screened a computer-generated list of patients who were admitted to non-critical care units with orders for routine point-of-care blood glucose testing. If the primary hospital team approved, then potentially eligible patients were approached in their hospital room for further screening and informed consent.

Subjects were randomly assigned with a computer-generated randomization scheme 1:1 in randomly permuted blocks of 2,4 , or 6 to receive either the Intervention or UC. The study statistician (H.Z.) generated the random allocation sequence. Group assignments were placed in sealed envelopes and revealed sequentially as subjects were randomized. Study coordinators enrolled participants and assigned them to interventions based on the allocation sequence.

\subsection{Usual Care and Intervention}

Subjects in the UC group received the standard discharge instructions, education, medication reconciliation, and follow-up according to routine practice. Discharge instructions were generated using the Epic Hyperspace ${ }^{\circledR}$ (Verona, WI, USA) electronic health record (EHR), which is integrated between the inpatient and outpatient settings. Education was provided by bedside nurses and hospital providers at their discretion using stock materials in the EHR (ExitCare Clinical References). Subjects received training by a bedside nurse on using a glucometer and insulin as needed. Diabetes therapy upon discharge was determined by the primary team. Discharge instructions were routinely sent to the primary care provider (PCP) either by fax or EHR. Subjects received a phone call within 4 days after discharge from a hospital-employed community health worker that included checking on the health of the subject, confirming follow-up appointments and access to medications, 
and answering questions. Problems were referred to a nurse navigator, all of whom had a nurse practitioner degree, for further management. A transition-of-care appointment was scheduled for all patients with a PCP within 10 days of discharge. This appointment focused on medication reconciliation, review of discharge instructions, and updating care needs since hospital discharge.

Subjects in the Intervention group received the DiaTOHC Program in addition to the UC described above. The DiaTOHC Program has three components: (1) patient-centered discharge education, (2) HbA1c-based adjustment of diabetes therapy upon discharge, and (3) post-discharge support.

\subsubsection{Patient-Centered Discharge Education}

The education consisted of two parts delivered by one of three study team navigators over the phone before discharge or 1 to 3 days after discharge according to subject availability. The first part was focused, customizable, diabetes discharge instructions and education using a 19-page booklet based on American Diabetes Association (ADA) guidelines that includes information on diet, physical activity, and self-care guidance, such as how to recognize and treat hypoglycemia and hyperglycemia [8]. The instructions addressing postdischarge use of diabetes medications were adapted from previously published work [9]. All the concepts tested in the revised Diabetes Knowledge Test (DKT2) are covered in the booklet [10]. Subjects who had not completed a formal outpatient diabetes education program in the prior 12 months were referred to a Diabetes Care and Education Specialist at the Temple Diabetes Center. The second part of discharge education was a comprehensive review of the discharge plan. A navigator reviewed the discharge plan with subjects, covering the treatment plan, how to take medications, reasons for and importance of follow-up appointments and testing, and how to reach post-hospital providers.

\subsubsection{HbA1c-Based Adjustment of Diabetes Therapy upon Discharge}

Diabetes therapy upon hospital discharge was determined by a study endocrinologist (C.V. or D.R.) using an algorithm based on previously published work and ADA guidelines (Supplementary Table S1) [8,11]. For subjects with baseline $\mathrm{HbA1c}<7.0 \%$ (53 mmol/mol), the preadmission treatment regimen was continued unless adjustments were needed for safety. For subjects with baseline $\mathrm{HbA1c}>7.0 \%$ (53 mmol/mol), preadmission non-insulin diabetes therapy was optimized, defined as using the next higher dose up to the maximum tolerated dose. Only FDA-approved diabetes therapies were used in the study. Metformin was started in subjects with Type 2 Diabetes who did not have a contraindication to using it. Depending on the baseline $\mathrm{HbA1c}$ level, insulin was adjusted or added to the preadmission regimen.

\subsubsection{Post-Discharge Support}

One to three days after discharge, a navigator called subjects to assess their status, confirm receipt of and compliance with medications, verify follow-up appointments, assess barriers to following the discharge plan, determine the need for a community health worker, and review BG levels. Similar phone calls were made weekly for four weeks following discharge or until the first unplanned readmission. Subjects who were discharged on non-insulin regimens were asked to check their BG levels at least once a day, and subjects discharged on insulin at least twice a day. If a subject reported BG levels $<70$ or $>240 \mathrm{mg} / \mathrm{dL}$ (3.9 or $13.3 \mathrm{mmol} / \mathrm{L}$ ), then the navigator notified a study physician, who contacted the subject by phone to adjust diabetes therapy per protocol (Supplementary Tables S2 and S3). In addition, all intervention subjects received a referral for a nursing visit in the home to assess medical needs for support at home. Referral to a community health worker was made if subjects were found to have non-medical needs and/or obstacles to maintaining self-care and attending follow-up appointments, including transportation, food, housing, financial, and legal issues. 


\subsection{Data Collection, Measures, and Sample Size}

The primary outcome was all-cause unplanned hospital readmission within 30 days of discharge. Secondary outcomes assessed at 30 days after discharge were rate of any emergency department (ED) visit not associated with a hospital admission, composite rate of unplanned readmission or ED visit, cost of post-discharge acute care and the intervention (details below), daily frequency of self-monitored blood glucose (SMBG) testing, and three categories of hypoglycemia defined as any SMBG level $<70,<54$, or $<40 \mathrm{mg} / \mathrm{dL}(3.9,3$, or $2.2 \mathrm{mmol} / \mathrm{L}$, Intervention group only). Data on hypoglycemia in the Intervention group were obtained during the follow-up navigator phone calls. Because the UC group did not receive navigator calls, comparable data on hypoglycemia were not available. Baseline characteristics were recorded based on self-report and review of the medical record.

Approximately 5 weeks after discharge, a study coordinator called subjects in both groups to assess readmissions, ED visits, and the frequency of SMBG testing. In addition, a novel patient experience questionnaire was administered to Intervention subjects. Subjects were asked to respond to each of the following statements with either Agree, Neutral, or Disagree: (1) "I understood my discharge instructions," (2) "The diabetes teaching in the booklet was helpful," and (3) "I was happy with the support I got after leaving the hospital." Healthcare encounters were confirmed in the EHR, which is integrated with several other healthcare systems in the region by Epic Care Everywhere. Readmissions that could not be confirmed in the EHR were confirmed by obtaining discharge records. Change in $\mathrm{HbA} 1 \mathrm{c}$ level from baseline (hospital admission) was assessed 3 months after discharge.

The cost of post-discharge acute care was based on the sum of the estimated cost of all planned and unplanned readmissions and ED visits within 30 days of discharge. The cost of each readmission was based on the observed length of stay and a unit cost of USD 3045 per hospital day in 2017 among patients with diabetes [12]. The cost of each ED visit was based on a unit cost of USD 1110 [12]. The cost of the intervention was based on the value of time spent by the navigators and study physicians. Based on the average annual income of a navigator working $2000 \mathrm{~h}$ per year, navigator time was valued at USD 58 per hour. Similarly, based on the fiscal year 2018 median income of an assistant professor in endocrinology working $2300 \mathrm{~h}$ per year in the United States, physician time was valued at USD 101 per hour [13].

A target of 60 subjects per group was the largest deemed feasible. The last date of enrollment was determined by navigator availability. As a pilot trial, this study is not powered to detect statistically significant differences in outcomes.

\subsection{Analysis}

Distributions of the data were assessed by descriptive statistical and graphical methods. Summary statistics are reported as mean \pm standard deviation or median (interquartile range). Because of skewed distributions, the ratio of estimated costs between groups was calculated using log-transformed gamma regression [14]. The primary analyses for all outcomes were performed in the intention-to-treat (ITT) population, defined as having been randomly assigned to a study group and not meeting post-enrollment exclusion criteria. In prespecified analyses, outcomes were assessed in the ITT subgroup of subjects with a baseline $\mathrm{HbA} 1 \mathrm{c}>7.0 \%(53 \mathrm{mmol} / \mathrm{mol})$. No statistical testing was performed for this pilot trial.

\section{Results}

\subsection{Participant Flow}

Between 16 October 2017 and 30 May 2019, a total of 3915 patients were assessed for eligibility and 3822 were excluded (Figure 1). The remaining 93 patients were randomized, and 47 were allocated to Intervention, 46 to UC. Because two subjects withdrew consent, the analyzed ITT cohort had 45 Intervention subjects and 46 UC subjects. 


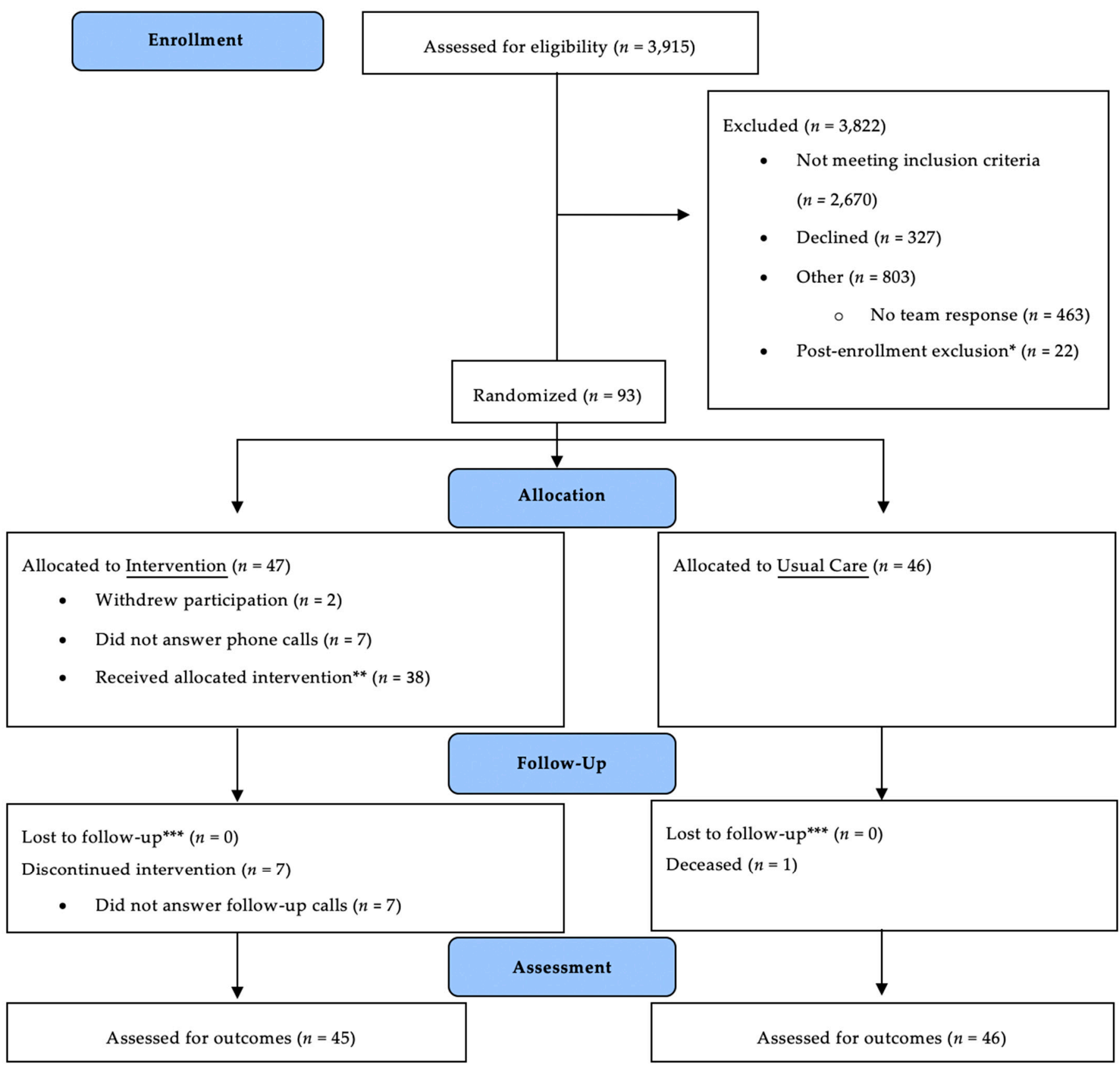

Figure 1. Flow of patients in trial. * Post-enrollment exclusion criteria were transfer to another hospital or subacute facility, discharge to hospice or a long-term care facility, signing out against medical advice, or inpatient death; ** Subject received education, adjustment of diabetes therapy upon discharge, and at least 1 follow-up phone call; ${ }^{* * *}$ Electronic health record used for follow-up if subject could not be contacted.

\subsection{Baseline Characteristics}

Mean age was $58.7 \pm 12.7$ years, duration of diabetes $15.1 \pm 10.0$ years, and median HbA1c $8.7 \%$ (7.1-10.6\%), $72 \mathrm{mmol} / \mathrm{mol}$ (54-92 mmol/mol) (Table 1). The cohort was $71 \%$ Black, $28 \%$ White, $14 \%$ Hispanic and mostly low-income (86\%). Most patients (95\%) had Type 2 Diabetes. Predicted 30-day readmission risk was similar between groups (38.4 $\pm 7.6 \%$ Intervention, $37.5 \pm 7.5 \%$ UC). 
Table 1. Baseline characteristics of Intervention and Usual Care groups.

\begin{tabular}{|c|c|c|c|}
\hline Variable & $\begin{array}{l}\text { All Patients } \\
\qquad N=91\end{array}$ & $\begin{array}{c}\text { Intervention } \\
\quad n=45\end{array}$ & $\begin{array}{c}\text { Usual Care } \\
n=46\end{array}$ \\
\hline Age, years & $58.7 \pm 12.7$ & $58.5 \pm 13.7$ & $58.9 \pm 11.7$ \\
\hline Female & 47 (51.6) & $21(46.7)$ & $26(56.5)$ \\
\hline \multicolumn{4}{|l|}{ Income, USD } \\
\hline Less than $\$ 12,060$ & $25(27.5)$ & $9(20.0)$ & $16(34.8)$ \\
\hline$\$ 12,060-\$ 16,239$ & $16(17.6)$ & $8(17.8)$ & $8(17.4)$ \\
\hline$\$ 16,240-\$ 24,599$ & $15(16.5)$ & $9(20.0)$ & $6(13.0)$ \\
\hline$\$ 24,600-\$ 49,999$ & $22(24.2)$ & $11(24.4)$ & $11(23.9)$ \\
\hline$\$ 50,000$ or more & $13(14.3)$ & $8(17.8)$ & $5(10.9)$ \\
\hline \multicolumn{4}{|l|}{ Race } \\
\hline Black & $65(71.4)$ & $29(64.4)$ & $36(78.3)$ \\
\hline Other & $1(1.1)$ & $0(0.0)$ & $1(2.2)$ \\
\hline White & $25(27.5)$ & $16(35.6)$ & $9(20.0)$ \\
\hline Hispanic & $13(14.3)$ & $9(20.0)$ & $4(8.7)$ \\
\hline Education, years & $12.6 \pm 2.5$ & $13.0 \pm 3.0$ & $12.1 \pm 1.8$ \\
\hline \multicolumn{4}{|l|}{ Employment Status } \\
\hline Disabled & $64(70.3)$ & $32(71.1)$ & $32(69.6)$ \\
\hline Employed & $1(1.1)$ & $1(2.2)$ & $0(0.0)$ \\
\hline Retired & $16(17.6)$ & $6(13.3)$ & $10(21.7)$ \\
\hline Unemployed & $10(11.0)$ & $6(13.3)$ & $4(8.7)$ \\
\hline \multicolumn{4}{|l|}{ Insurance } \\
\hline Medicaid only & $16(18.0)$ & $9(20.9)$ & $7(15.2)$ \\
\hline Medicare and Medicaid & $17(19.1)$ & $9(20.9)$ & $8(17.4)$ \\
\hline Medicare only & $24(27.0)$ & $10(23.3)$ & $14(30.4)$ \\
\hline None & $3(3.4)$ & $2(4.7)$ & $1(2.2)$ \\
\hline Private & $29(32.6)$ & $13(30.2)$ & $16(34.8)$ \\
\hline \multicolumn{4}{|l|}{ Smoking } \\
\hline Current smoker & $18(19.8)$ & $9(20.0)$ & $9(19.6)$ \\
\hline Former smoker & $40(44.0)$ & $20(44.4)$ & $20(43.5)$ \\
\hline Never & $33(36.3)$ & $16(35.6)$ & $17(37.0)$ \\
\hline Body mass index $\left(\mathrm{kg} / \mathrm{m}^{2}\right)$ & $35.2 \pm 10.9$ & $36.2 \pm 11.7$ & $34.2 \pm 10.0$ \\
\hline \multicolumn{4}{|l|}{ Type of Diabetes } \\
\hline Type 1 & $5(5.5)$ & $3(6.7)$ & $2(4.3)$ \\
\hline Type 2 & $86(94.5)$ & $42(93.3)$ & $44(95.7)$ \\
\hline Diabetes duration, years & $15.1 \pm 10.0$ & $13.6 \pm 8.5$ & $16.6 \pm 11.2$ \\
\hline A1c at admission & $8.7(7.1-10.6)$ & $8.9(7.2-11.1)$ & $8.5(7.1-10.0)$ \\
\hline A1c at admission $>7.0 \%(53 \mathrm{mmol} / \mathrm{mol})$ & $69(76.7)$ & $34(77.3)$ & $35(76.1)$ \\
\hline \multicolumn{4}{|l|}{ Preadmission Home Medication Route } \\
\hline Insulin only & $52(57.1)$ & $27(60.0)$ & $25(54.3)$ \\
\hline No medications & $7(7.7)$ & $1(2.2)$ & $6(13.0)$ \\
\hline Oral \& insulin & $19(20.9)$ & $13(28.9)$ & $6(13.0)$ \\
\hline Oral only & $11(12.1)$ & $3(6.7)$ & $8(17.4)$ \\
\hline Other & $2(2.2)$ & $1(2.2)$ & $1(2.2)$ \\
\hline Preadmission sulfonylurea use & $8(8.8)$ & $3(6.7)$ & $5(10.9)$ \\
\hline Preadmission metformin use & $19(20.9)$ & $9(20.0)$ & $10(21.7)$ \\
\hline Preadmission insulin use & $73(80.2)$ & $42(93.3)$ & $31(67.4)$ \\
\hline Preadmission statin use & $64(70.3)$ & $28(62.2)$ & $36(78.3)$ \\
\hline Preadmission glucocorticoid use & $18(19.8)$ & $8(17.8)$ & $10(21.7)$ \\
\hline \multicolumn{4}{|l|}{ Preadmission blood pressure medications } \\
\hline None & $14(15.4)$ & $9(20.0)$ & $5(10.9)$ \\
\hline ACE-i or ARB and Non-ACE/ARB & $25(27.5)$ & $13(28.9)$ & $12(26.1)$ \\
\hline Only ACE-i or ARB & $23(25.3)$ & $6(13.3)$ & $17(37.0)$ \\
\hline Only non-ACE or ARB & $29(31.9)$ & $17(37.8)$ & $12(26.1)$ \\
\hline History of severe hypoglycemia & $34(37.8)$ & $17(37.8)$ & $17(37.8)$ \\
\hline Current or prior DKA or HHS & $9(9.9)$ & $5(11.1)$ & $4(8.7)$ \\
\hline
\end{tabular}


Table 1. Cont.

\begin{tabular}{|c|c|c|c|}
\hline Variable & $\begin{array}{l}\text { All Patients } \\
\qquad N=91\end{array}$ & $\begin{array}{c}\text { Intervention } \\
\quad n=45\end{array}$ & $\begin{array}{c}\text { Usual Care } \\
\qquad n=46\end{array}$ \\
\hline \multicolumn{4}{|l|}{ Microvascular complications } \\
\hline 0 & $35(38.5)$ & $15(33.3)$ & $20(43.5)$ \\
\hline 1 & $35(38.5)$ & $20(44.4)$ & $15(32.6)$ \\
\hline 2 & $15(16.5)$ & $7(15.6)$ & $8(17.4)$ \\
\hline 3 & $6(6.6)$ & $3(6.7)$ & $3(6.5)$ \\
\hline \multicolumn{4}{|l|}{ Macrovascular complications } \\
\hline 0 & $25(27.5)$ & $13(28.9)$ & $12(26.1)$ \\
\hline 1 & $38(41.8)$ & $20(44.4)$ & $18(39.1)$ \\
\hline 2 & $21(23.1)$ & $9(20.0)$ & $12(26.1)$ \\
\hline 3 & $6(6.6)$ & $2(4.4)$ & $4(8.7)$ \\
\hline 4 & $1(1.1)$ & $1(2.2)$ & $0(0.0)$ \\
\hline Anemia diagnosis & $62(68.1)$ & $33(73.3)$ & $29(63.0)$ \\
\hline $\begin{array}{l}\text { Discharged within } 90 \text { days before index } \\
\text { admission }\end{array}$ & $81(89.0)$ & $45(100.0)$ & $36(78.3)$ \\
\hline ED visit within 90 days before index admission & $24(30.4)$ & $10(26.3)$ & $14(34.1)$ \\
\hline \multicolumn{4}{|l|}{ Admission priority } \\
\hline Emergent & $75(82.4)$ & $37(82.2)$ & $38(82.6)$ \\
\hline Planned & $4(4.4)$ & $2(4.4)$ & $2(4.3)$ \\
\hline Urgent & $12(13.2)$ & $6(13.3)$ & $6(13.0)$ \\
\hline Home zip code within 5 miles of hospital & $78(85.7)$ & $40(88.9)$ & $38(82.6)$ \\
\hline \multicolumn{4}{|l|}{ Discharge status } \\
\hline Against medical advice & $1(1.1)$ & $0(0.0)$ & $1(2.2)$ \\
\hline Home with nursing care & $28(30.8)$ & $14(31.1)$ & $14(30.4)$ \\
\hline Home without additional services & $56(61.5)$ & $29(64.4)$ & $27(58.7)$ \\
\hline $\begin{array}{l}\text { Subacute facility (rehabilitation or } \\
\text { skilled nursing) }\end{array}$ & $5(5.5)$ & $2(4.4)$ & $3(6.5)$ \\
\hline No discharge within prior year & $1(1.1)$ & $0(0.0)$ & $1(2.2)$ \\
\hline Predicted risk of readmission within 30 days, $\%$ & $38.4 \pm 7.6$ & $39.2 \pm 7.8$ & $37.5 \pm 7.5$ \\
\hline Admission blood glucose, $\mathrm{mg} / \mathrm{dL}$ & $208.1 \pm 107.7$ & $188.7 \pm 95.6$ & $227.1 \pm 116.4$ \\
\hline Admission blood glucose, $\mathrm{mmol} / \mathrm{L}$ & $11.6 \pm 6.0$ & $10.5 \pm 5.3$ & $12.6 \pm 6.5$ \\
\hline Admission serum sodium, $\mathrm{mmol} / \mathrm{L}$ & $136.0 \pm 4.9$ & $136.3 \pm 4.9$ & $135.7 \pm 5.0$ \\
\hline Admission serum potassium, $\mathrm{mmol} / \mathrm{L}$ & $4.3 \pm 0.8$ & $4.3 \pm 0.9$ & $4.2 \pm 0.7$ \\
\hline Admission serum creatinine, $\mathrm{mg} / \mathrm{dL}$ & $1.7(1.1-3.2)$ & $2.0(1.1-3.2)$ & $1.5(1.1-3.2)$ \\
\hline Admission eGFR, $\mathrm{mL} / \mathrm{min}$ & $39.8 \pm 20.6$ & $39.8 \pm 20.5$ & $39.8 \pm 20.9$ \\
\hline \multicolumn{4}{|l|}{ Admission hematocrit, $\%$} \\
\hline High & $2(2.2)$ & $2(4.4)$ & $0(0.0)$ \\
\hline Low & $69(75.8)$ & $30(66.7)$ & $39(84.8)$ \\
\hline Normal & $20(22.0)$ & $13(28.9)$ & $7(15.2)$ \\
\hline Brief Health Literacy Screen Score & $11.9 \pm 2.9$ & $12.3 \pm 3.0$ & $11.6 \pm 2.7$ \\
\hline PHQ-2 Score & $1.0(0.0-2.0)$ & $1.0(0.0-2.0)$ & $2.0(1.0-3.0)$ \\
\hline Diabetes Knowledge Test Score & $57.3 \pm 15.6$ & $59.1 \pm 15.7$ & $55.5 \pm 15.5$ \\
\hline Problem Areas in Diabetes Score & $30.6 \pm 24.3$ & $36.3 \pm 25.1$ & $25.1 \pm 22.4$ \\
\hline Predicted risk of readmission within 30 days, $\%$ * & $38.4 \pm 7.6$ & $39.2 \pm 7.8$ & $37.5 \pm 7.5$ \\
\hline
\end{tabular}

Values are mean \pm SD, median (IQR), or $n(\%)$ unless otherwise stated. ${ }^{*}$ Predicted risk based on Diabetes Early Readmission Risk Indicator (DERRI ${ }^{\mathrm{TM}}$ ). IQR (interquartile range), ACE-i (angiotensin-converting enzyme inhibitors), ARB (angiotensin II receptor blockers), DKA (diabetic ketoacidosis), HHS (hyperosmolar hyperglycemic state), eGFR (estimated glomerular filtration rate), PHQ (patient health questionnaire).

\subsection{Outcomes}

The 30-day readmission rate was $31.1 \%$ in the Intervention group and $32.6 \%$ in the UC group (Table 2). The combined 30-day readmission or ED visit rate was $35.6 \%$ in the Intervention group and 39.1\% in the UC group. The number of SMBG tests was $2.4 \pm 1.6$ per day in the Intervention group and $1.8 \pm 1.4$ per day in the UC group. Costs in the Intervention group were $33 \%$ of the costs in the UC group. Only $11 \%$ of Intervention participants reported having at least one BG level $<70 \mathrm{mg} / \mathrm{dL}(3.9 \mathrm{mmol} / \mathrm{L})$ during followup. Change in $\mathrm{HbA1c}$ was similar at 3 months between the two groups. Among survey respondents in the Intervention group, 97\% understood their discharge instructions, 93\% 
believed the diabetes teaching was helpful, and 93\% were happy with the support they received after leaving the hospital.

Table 2. Outcomes in Intervention and Usual care groups.

\begin{tabular}{|c|c|c|c|}
\hline \multicolumn{4}{|l|}{ Intention-to-Treat Cohort } \\
\hline Variable $^{a}$ & $\begin{array}{l}\text { All Patients } \\
\qquad N=91\end{array}$ & $\begin{array}{c}\text { Intervention } \\
\quad n=45\end{array}$ & $\begin{array}{c}\text { Usual Care } \\
n=46\end{array}$ \\
\hline Readmission & $29(31.9)$ & $14(31.1)$ & $15(32.6)$ \\
\hline ED visit & $8(8.8)$ & $4(8.9)$ & $4(8.7)$ \\
\hline Readmission or ED visit & $34(37.4)$ & $16(35.6)$ & $18(39.1)$ \\
\hline Costs, USD & - & $5542 \pm 10,970$ & $6657 \pm 16,969$ \\
\hline Costs, USD & - & $172(127-5546)$ & $0(0-5667)$ \\
\hline Costs, Intervention:Usual Care ratio ${ }^{b}(95 \% \mathrm{CI})$ & & $0.33(0.13-0.79)$ & \\
\hline \multicolumn{4}{|l|}{ Hypoglycemia } \\
\hline -Blood glucose $<70 \mathrm{mg} / \mathrm{dL}(3.9 \mathrm{mmol} / \mathrm{L})$ & - & $5(11)$ & - \\
\hline -Blood glucose $<54 \mathrm{mg} / \mathrm{dL}(3.0 \mathrm{mmol} / \mathrm{L})$ & - & $2(4)$ & - \\
\hline -Blood glucose $<40 \mathrm{mg} / \mathrm{dL}(2.2 \mathrm{mmol} / \mathrm{L})$ & - & $1(2)$ & - \\
\hline Number of daily SMBG tests & $2.1 \pm 1.5$ & $2.4 \pm 1.6$ & $1.8 \pm 1.4$ \\
\hline Change in $\mathrm{HbA} 1 \mathrm{c}$ at 3 months, $\%$ & $-0.9(-1.6-0.2)$ & $-1.0(-1.6-0.2)$ & $-0.9(-1.4-0.2)$ \\
\hline Change in $\mathrm{HbA} 1 \mathrm{c}$ at 3 months, $\mathrm{mmol} / \mathrm{mol}$ & $-10(-18-2)$ & $-11(-18-2)$ & $-10(-15-2)$ \\
\hline Subgroup with baseline $\mathrm{HbA} 1 \mathrm{c}>7.0 \%$ & $\begin{array}{l}\text { All Patients } \\
\qquad N=69\end{array}$ & $\begin{array}{l}\text { Intervention } \\
\quad n=34\end{array}$ & $\begin{array}{c}\text { Usual Care } \\
n=35\end{array}$ \\
\hline Readmission & $19(27.5)$ & $8(23.5)$ & $11(31.4)$ \\
\hline ED visit & $7(10.1)$ & $3(8.8)$ & $4(11.4)$ \\
\hline Readmission or ED visit & $23(33.3)$ & $9(26.5)$ & $14(40.0)$ \\
\hline Costs, USD & - & $3657 \pm 8230$ & $6967 \pm 18,863$ \\
\hline Costs, USD & - & $154(126-1246)$ & $0(0-5661)$ \\
\hline Costs, Intervention:Usual Care ratio ${ }^{b}(95 \% C I)$ & & $0.21(0.08-0.58)$ & \\
\hline Hypoglycemia & & & \\
\hline -Blood glucose $<70 \mathrm{mg} / \mathrm{dL}(3.9 \mathrm{mmol} / \mathrm{L})$ & - & $5(14.7)$ & - \\
\hline -Blood glucose $<54 \mathrm{mg} / \mathrm{dL}(3.0 \mathrm{mmol} / \mathrm{L})$ & - & $2(5.9)$ & - \\
\hline -Blood glucose $<40 \mathrm{mg} / \mathrm{dL}(2.2 \mathrm{mmol} / \mathrm{L})$ & - & $1(2.9)$ & - \\
\hline Number of daily SMBG tests & $2.2 \pm 1.6$ & $2.5 \pm 1.6$ & $2.0 \pm 1.5$ \\
\hline Change in $\mathrm{HbA} 1 \mathrm{c}$ at 3 months, $\%$ & $-1.0(-2.2-0.0)$ & $-1.1(-2.2-0.0)$ & $-0.9(-2.3-0.1)$ \\
\hline Change in $\mathrm{HbA} 1 \mathrm{c}$ at 3 months, $\mathrm{mmol} / \mathrm{mol}$ & $-11(-24-0)$ & $-12(-24-0)$ & $-10(-25-1)$ \\
\hline
\end{tabular}

Values are mean $\pm \mathrm{SD}$, median (IQR), or $n(\%)$ unless otherwise stated. IQR, interquartile range; $\mathrm{CI}$, confidence interval. ${ }^{a}$ Within the 30 days after hospital discharge. ${ }^{\mathrm{b}}$ Costs of 30-day readmissions, ED visits, and the intervention. SMBG, self-monitored blood glucose.

\subsection{Ancillary Analysis}

Among the 69 subjects with baseline $\mathrm{HbA} 1 \mathrm{c}>7.0 \%$ (53 mmol $/ \mathrm{mol})$, the 30-day readmission rate was $23.5 \%$ in the Intervention group and $31.4 \%$ in the UC group (Table 2). The combined 30-day readmission or ED visit rate was $26.5 \%$ in the Intervention group and $40.0 \%$ in the UC group. Among the Intervention participants, $15 \%$ reported having at least one BG level $<70 \mathrm{mg} / \mathrm{dL}(3.9 \mathrm{mmol} / \mathrm{L})$ during follow-up. The number of SMBG tests was $2.5 \pm 1.6$ per day in the Intervention group and $2.0 \pm 1.5$ per day in the UC group. Costs in the Intervention group were $21 \%$ of the costs in the UC group. Change in $\mathrm{HbA} 1 \mathrm{c}$ was similar at 3 months between the two groups.

\section{Discussion}

This pilot RCT suggests the DiaTOHC intervention, with which participants were overwhelmingly satisfied, may be feasible at an urban, academic, safety-net hospital. Readmission rates in the Intervention and UC groups were similar. However, the trial raises the possibility that the intervention may decrease readmission/ED visit risk among patients with a baseline $\mathrm{HbA} 1 \mathrm{c}>7.0 \%$ (53 $\mathrm{mmol} / \mathrm{mol})$. In this subgroup, Intervention subjects experienced a $34 \%$ relative risk reduction in readmission/ED visit risk and absolute risk 
reduction of $13.5 \%$. Additionally, costs were substantially lower in the Intervention group. Furthermore, hypoglycemia during the intervention was uncommon, with $11 \%$ of Intervention participants reporting any SMBG $<70 \mathrm{mg} / \mathrm{dL}(3.9 \mathrm{mmol} / \mathrm{L})$. Other trials with similar $\mathrm{HbA} 1 \mathrm{c}-$ based discharge treatment algorithms reported post-discharge hypoglycemia rates of $23-29 \%[11,15]$.

Several mostly observational studies have investigated the effect of various interventions on readmission risk in diabetes patients [4], categorizable as inpatient diabetes education only, inpatient diabetes management by a dedicated service, and multi-component programs consisting of education, transition-of-care support, and/or outpatient follow-up. The relative risk reductions of these interventions vary considerably from 0 to $71 \%$, with most studies showing benefit.

The current study adds to the small number of related published RCTs with a novel approach: combining multi-component intervention with selection of high-risk patients using a validated tool. This pilot study, however, is limited by lacking power for detecting differences between groups. Because observation of the UC group was limited, we were unable to compare hypoglycemia rates or office visits between groups. Given the nature of the intervention, blinding was not feasible. In addition, the statisticians were not blinded. Lastly, the findings may not generalize to other sites and settings.

In conclusion, the possible reduction in 30-day readmission/ED visit risk in the higher $\mathrm{HbA1c}$ subgroup merits further investigation in a larger, multi-center RCT.

Supplementary Materials: The following supporting information can be downloaded at: https: / / www.mdpi.com/article/10.3390/jcm11061471/s1, Table S1: HbA1c-based adjustment of diabetes therapy; Table S2: Outpatient basal insulin dose adjustment; Table S3: Outpatient prandial/pre-meal insulin dose adjustment based on subsequent mealtime/HS BG values [16].

Author Contributions: D.J.R. conceived of the study and wrote the manuscript. S.W., C.V., D.R., F.D., A.K., N.K. and S.A. collected data. A.D. collected data and edited the manuscript. P.G. wrote the manuscript. M.D.N. and S.H.G. contributed to study design, discussion, and reviewed/edited the manuscript. H.Z. and J.W. conducted statistical analyses. All authors have read and agreed to the published version of the manuscript.

Funding: This research was funded by the National Institutes of Health, grant numbers K23DK102963 and R01DK122073. The content is solely the responsibility of the authors and does not necessarily represent the official views of the National Institutes of Health.

Institutional Review Board Statement: The study was conducted in accordance with the Declaration of Helsinki and approved by the Institutional Review Board of Temple University (protocol code 24306, approved on 24 May 2017).

Informed Consent Statement: Informed consent was obtained from all subjects involved in the study.

Data Availability Statement: Data are available on request due to restrictions on sharing of protected health information.

Acknowledgments: This study was published in abstract form at the ADA 79th Scientific Sessions in 2019 .

Conflicts of Interest: D.R. received unrelated research funding from AstraZeneca. S.G. is a member of the Medtronic, Inc. Health Equity Advisory Board and ADA National Board of Directors. The other authors declare no conflict of interest. The funder had no role in the design of the study; in the collection, analyses, or interpretation of data; in the writing of the manuscript, or in the decision to publish the results. 


\section{References}

1. Benbassat, J.; Taragin, M. Hospital readmissions as a measure of quality of health care: Advantages and limitations. Arch. Intern. Med. 2000, 160, 1074-1081. [CrossRef] [PubMed]

2. Rubin, D.J. Hospital Readmission of Patients with Diabetes. Curr. Diabetes Rep. 2015, 15, 17. [CrossRef] [PubMed]

3. Enomoto, L.M.; Shrestha, D.P.; Rosenthal, M.B.; Hollenbeak, C.S.; Gabbay, R.A. Risk factors associated with 30-day readmission and length of stay in patients with type 2 diabetes. J. Diabetes Complicat. 2017, 31, 122-127. [CrossRef] [PubMed]

4. Rubin, D.J.; Shah, A.A. Predicting and Preventing Acute Care Re-Utilization by Patients with Diabetes. Curr. Diabetes Rep. 2021, 21, 34. [CrossRef] [PubMed]

5. $\quad$ Rubin, D.J.; Handorf, E.A.; Golden, S.H.; Nelson, D.B.; McDonnell, M.E.; Zhao, H. Development and Validation of a Novel Tool to Predict Hospital Readmission Risk Among Patients With Diabetes. Endocr. Pract. 2016, 22, 1204-1215. [CrossRef] [PubMed]

6. Rubin, D.J. The Diabetes Early Readmission Risk Indicator (DERRI ${ }^{\mathrm{TM}}$ ). 2016. Available online: https://redcap.templehealth.org/ redcap/surveys/?s=3XCPCAMKWE (accessed on 23 August 2020).

7. Rubin, D.J.; Recco, D.; Turchin, A.; Zhao, H.; Golden, S.H. External Validation of the Diabetes Early Re-Admission Risk Indicator (DERRI ${ }^{\mathrm{TM}}$ ). Endocr. Pract. 2018, 24, 527-541. [CrossRef] [PubMed]

8. ADA. Standards of Medical Care in Diabetes-2016. Diabetes Care 2016, 39 (Suppl. 1), S52-S58.

9. Lauster, C.D.; Gibson, J.M.; DiNella, J.V.; DiNardo, M.; Korytkowski, M.T.; Donihi, A.C. Implementation of standardized instructions for insulin at hospital discharge. J. Hosp. Med. 2009, 4, E41-E42. [CrossRef] [PubMed]

10. Fitzgerald, J.T.; Funnell, M.M.; Anderson, R.M.; Nwankwo, R.; Stansfield, R.B.; Piatt, G.A. Validation of the Revised Brief Diabetes Knowledge Test (DKT2). Diabetes Educator. 2016, 42, 178-187. [CrossRef] [PubMed]

11. Umpierrez, G.E.; Reyes, D.; Smiley, D.; Hermayer, K.; Khan, A.; Olson, D.E.; Pasquel, F.; Jacobs, S.; Newton, C.; Peng, L.; et al. Hospital Discharge Algorithm Based on Admission $\mathrm{HbA}_{1 \mathrm{c}}$ for the Management of Patients With Type 2 Diabetes. Diabetes Care 2014, 37, 2934-2939. [CrossRef] [PubMed]

12. ADA. Economic Costs of Diabetes in the U.S. in 2017. Diabetes Care 2018, 41, 917-928. [CrossRef] [PubMed]

13. MGMA. MGMA 2019 Academic Total Compensation (by Rank); Medical Group Management Association: Englewood, CO, USA, 2019.

14. Blough, D.K.; Ramsey, S.D. Using Generalized Linear Models to Assess Medical Care Costs. Health Serv. Outcomes Res. Methodol. 2000, 1, 185-202. [CrossRef]

15. Gianchandani, R.Y.; Pasquel, F.J.; Rubin, D.J.; Dungan, K.M.; Vellanki, P.; Wang, H.; Anzola, I.; Gomez, P.; Hodish, I.; LathkarPradhan, S.; et al. The Efficacy and Safety of Co-Administration of Sitagliptin with Metformin in Patients with Type 2 Diabetes at Hospital Discharge. Endocr. Pract. 2018, 24, 556-564. [CrossRef] [PubMed]

16. Eldridge, S.M.; Chan, C.L.; Campbell, M.J.; Bond, C.M.; Hopewell, S.; Thabane, L.; Lancaster, G.A.; on behalf of the PAFS consensus group. CONSORT 2010 statement: Extension to randomised pilot and feasibility trials. BMJ 2016, 355, i5239. [CrossRef] [PubMed] 